\title{
Expanding the breadth of Medicare: learning from Australia
}

\author{
STEPHEN DUCKETT* \\ Director, Health Program, Grattan Institute, Carlton, Victoria, Australia
}

\begin{abstract}
The design of Australia's Medicare programme was based on the Canadian scheme, adapted somewhat to take account of differences in the constitutional division of powers in the two countries and differences in history. The key elements are very similar: access to hospital services without charge being the core similarity, universal coverage for necessary medical services, albeit with a variable co-payment in Australia, the other. But there are significant differences between the two countries in health programmes - whether or not they are labelled as 'Medicare'. This paper discusses four areas where Canada could potentially learn from Australia in a positive way. First, Australia has had a national Pharmaceutical Benefits Scheme for almost 70 years. Second, there have been hesitant extensions to Australia's Medicare to address the increasing prevalence of people with chronic conditions extensions which include some payments for allied health professionals, 'care coordination' payments, and exploration of 'health care homes'. Third, Australia has a much more extensive system of support for older people to live in their homes or to move into supported residential care. Fourth, Australia has gone further in driving efficiency in the hospital sector than has Canada. Finally, the paper examines aspects of the Australian health care system that Canada should avoid, including the very high level of out-of-pocket costs, and the role of private acute inpatient provision.
\end{abstract}

Submitted 1 April 2017; revised 19 May 2017; accepted 1 July 2017;

first published online 24 January 2018

\section{Introduction}

Australia and Canada share many similarities including a federal system, a colonial past and a somewhat-national health insurance scheme called Medicare. Australia's Medicare was modelled on Canada's (Scotton and Macdonald, 1993), but with important modifications to take account of Australia's contemporary health system, history and constitution.

In both countries, this universal health insurance system ensures that patients have access to hospitals without any financial barriers - in Australia this access is

\footnotetext{
*Correspondence to: Stephen Duckett, Director, Health Program, Grattan Institute, 8 Malvina Place, Carlton 3053, Victoria, Australia. Email: stephen.duckett@grattan.edu.au
} 
to 'public hospitals' which account for about two-thirds of all beds, and include the major academic medical centres - and access to medical services, which are generally provided by independent medical practitioners (not employed by government) who are primarily rewarded on a fee-for-service basis. Funding for these services comes from government. In Australia there is an identified 'Medicare levy', but this is not currently hypothecated to health care, although the 2017 Commonwealth budget provided that it would be allocated to a 'Medicare Guarantee Fund' (Duckett, 2017). Legislation to establish the Medicare Guarantee Fund had not been introduced into parliament at the date of writing (June 2017).

The two countries share a democratic, Westminster style of government, and are roughly comparable in terms of wealth (Canadian gross domestic product per capita in 2015 was $\$ 45,415$ compared with Australia's of $\$ 47,758$; both in US\$ purchasing power parity). Canada's population in 2017 is somewhat larger than Australia's (36 vs 23 million), and both are large geographically but with low average population density (Canada at 3.5 people $/ \mathrm{km}^{2}$; Australia at 3.1 people $/ \mathrm{km}^{2}$ ). The population of both, though, is concentrated: in Canada in the south of the country, in Australia along the Eastern seaboard and the south-west corner. The demography of Canada and Australia is similar, with both facing ageing populations and poorer health outcomes for Indigenous populations.

These similarities of history (majority), language and national wealth, and the similar Medicare arrangements mean that the health systems in the two countries are closer in structure than any other pairing for both Canada and Australia and have often led to the two nations being part of: comparative studies of aspects of system performance (Morgan et al., 2006; Clement et al., 2009; Tempier et al., 2009; Coleman et al., 2011; Sunderland et al., 2015); system organisational arrangements (Philippon and Braithwaite, 2008; Elson, 2009; Suchowersky et al., 2012); contracting and accountability for Indigenous health care (Lavoie, 2004; Lavoie et al., 2010; Dwyer et al., 2011; Tenbensel et al., 2014); as well as a number of whole system comparative publications (Duckett, 1983; Crichton, 1995; Crichton, 1998; Duckett, 2015). Australia and Canada were two of the original five nations included in the Commonwealth Fund's International Health Policy survey, the others being New Zealand, the United Kingdom and the United States (Donelan et al., 1999; Schoen et al., 2000), and Australia remains one of the 11 countries in the contemporary surveys (Osborn et al., 2016).

This paper is the first to identify whole system lessons for Canada from the Australian health system.

Australia's constitution gives the federal ('Commonwealth') government power to make laws about hospital and pharmaceutical benefits and, subject to certain constraints, medical services and for those laws to take precedence over state laws (McMillan, 1992; Wheelwright, 1995). It also gives the Commonwealth exclusive power to levy excise and effectively to crowd the states out of income taxation (Mathews and Jay, 1972). The term 'states' is used in this paper to refer to Australia's six states and two mainland territories. 
Responsibility for health care in Australia is shared between the Commonwealth government-responsible for subsidising medical services, pharmaceuticals, private health insurance and aged care - and the states which are responsible for public hospitals, although the Commonwealth provides grants to the states which cover about $40 \%$ of the costs of public hospitals (Duckett, 2014). The dual responsibility and the revenue squeeze on the states have resulted in regular and unedifying financial stoushes between the Commonwealth and state governments over the share of public hospital costs met by the Commonwealth government. These exchanges have dominated the Australian health care debate and led to cost and blame shifting (House of Representatives. Standing Committee on Health and Ageing, 2006), to the detriment of political accountability and resulting in a somewhat confusing system of gaps and overlaps in services (Swerissen and Duckett, 2007), which one commentator has dubbed 'marble cake federalism' (Wiltshire, 1992).

A distinguishing characteristic of Australian health care is the strong role played by the private sector in hospital provision (discussed below), with the business model of private hospitals underpinned by private health insurance, which is in turn subsidised by the Commonwealth government. About 47\% of Australians have some form of private health insurance.

Out of this morass has emerged substantial innovation in health care delivery and funding, and a health system which has relatively good outcomes, at least as measured in terms of average life expectancy, and this has been achieved at an affordable cost (Duckett and Willcox, 2015). Health status for Australia's Indigenous population is poor, and, although there are methodological difficulties in making comparisons (Australian Institute of Health and Welfare, 2011), probably relatively poorer than First Nations people in Canada (Anderson et al., 2016). Consequently, lessons to be learned are probably from Canada to Australia rather than vice versa in this regard.

Typical criteria to evaluate health system performance include equity, quality, efficiency and acceptability (e.g. see Duckett and Willcox, 2015). Two of these criteria, equity and efficiency, have been used to select four areas where Canada can learn from Australia: the Pharmaceutical Benefits Scheme (PBS); innovations in care for people with chronic conditions; support for the frail elderly; and funding policy for hospital care. These developments have all been generally positive on the two criteria. Not so positive has been Australia's experience with out-of-pocket costs for health care (failing significantly on the equity criterion) and the role of private insurance and private provision (failing on both criteria).

\section{The PBS}

The Australian PBS has positive lessons for Canada, as a relatively efficient way of providing access to pharmaceuticals. It was introduced on 1 July 1948 as part 
of post Second World War expansion of social provision. Relatively few prescriptions were provided under this scheme initially because of opposition from the medical profession. The Liberal (conservative) Government elected in 1949 altered the scheme, introducing a list of 139 'life saving and disease preventing drugs' that were provided free of charge to the whole community (Sloan, 1995). Since then, the range of drugs covered by the PBS has expanded significantly with new drugs being added each year. In 2014-2015 government spending on the PBS totalled A \$7.9 billion for 207 million subsidised prescriptions (PBS Information Management Section, 2016). This amounts to an annual government subsidy of $\mathrm{A} \$ 332$ per person, with the average person receiving 8.7 prescriptions each year.

The PBS incorporates defined mandatory co-payments with co-payments for each prescription for low income and social security beneficiaries set at A\$6.30 (as at 1 January 2017), other people at A $\$ 38.80$, and a 'safety net' under which high users pay either no co-payment or a reduced co-payment after meeting a specified threshold of prescriptions (or prescription co-payments) each year. These mandatory co-payments have equity implications, discussed in the section on co-payments below.

The decision to list an item on the PBS can lead to commitment of significant government expenditure. Australia pioneered the 'fourth hurdle' for listing new drugs, requiring demonstrable value for money supplementing the standard international expectations of quality, safety and efficacy (Mullins et al., 2003; Schwarzer et al., 2015).

Under the PBS cost-effectiveness arrangements, which have prevailed since 1993, pharmaceutical manufacturers' proposals for listing include cost-effectiveness data (Birkett et al., 2001; Bulfone et al., 2009). Although there are no explicit thresholds used in decision-making (Bulfone et al., 2009), a retrospective study of the decisionmaking process showed that in the early 1990s new pharmaceuticals costing more than $\$ 68,913$ per life year saved were generally not listed on the PBS, while those costing less than $\$ 36,450$ were listed (George et al., 2001). No apparent decision rules have been found to apply to the intermediate zone.

The Australian government, through the PBS, is a near monopsonistic purchaser for out-of-hospital pharmaceuticals. It has used this power in recent years to drive the price of pharmaceuticals down to approximate international benchmark pricing (Duckett and Banerjee, 2017). On average, Australian pharmaceutical prices appear to be about one-third of Canadian (Alberta and Ontario) prices (Duckett and Banerjee, 2017). For example, the wholesale price for a packet of $3040 \mathrm{mg}$ tablets for atorvastatin is A \$12.97 in Canada and A\$3.43 in Australia.

Canada is still struggling to introduce a universal pharmaceutical scheme (Gagnon, 2010; Boothe, 2012; O’Brady et al., 2015; Morgan and Boothe, 2016; Morgan et al., 2016) and could well draw on lessons from Australia about a scheme which provides universal coverage, at a reasonable cost, albeit with 
structured co-payments. The main lessons for Canada in the design of a new Pharmacare scheme are:

- The scheme should involve rigorous assessment of what is included in a national formulary, including assessing cost-effectiveness of listed drugs.

- Monoposonistic purchasing helps to depress prices.

- Strategies to ensure rational prescribing and avoid over-prescribing (described as 'quality use of medicines' in Australia) should be introduced (Smith and McGettigan, 2000; Weekes et al., 2005; Beilby et al., 2006); see also Rosen (2018) on similar strategies in Israel.

Recognising Canada's more decentralised health system, provincial variation could include provinces being able to set different incremental cost-effectiveness ratios for listed drugs, different co-payments and different payments to pharmacists.

Australia's PBS provides negative lessons too. Mandatory co-payments can have equity and access implications (see discussion of out-of-pocket costs below) and so care would need to be taken if they are an integral part of the design. A new Canadian Pharmacare programme could improve on some of the identified weaknesses of the Australian PBS, particularly on pricing where Australian prices are higher than some other countries (UK, New Zealand), in addition to going further than Australia's quite modest use of therapeutic equivalence or 'reference' pricing (Bulfone et al., 2009; Acosta et al., 2014; Duckett and Banerjee, 2017).

\section{Management of chronic conditions}

In common with the situation in other countries, the health needs of the Australian population are changing as more people experience chronic disease. Threequarters of Australians over the age of 65 now have one or more chronic disease and $90 \%$ of Australians die from chronic disease (Swerissen and Duckett, 2016). Australia has developed a series of initiatives to change the way family physicians work through targeted financial incentives, potentially providing lessons for Canada about improving efficiency in family practice in the way care for people with chronic illnesses is provided.

Australia's Medicare Benefits Scheme (MBS) arrangements are still dominated by fee-for-service reimbursement, a system which 'encourages reactive rather than systematic care' (Harris and Zwar, 2007). However, the Commonwealth Government, responsible for the design and funding of the MBS, has recognised the importance of introducing other modes of payments for general practitioners to encourage different practice patterns, including introducing incentives for better management of chronic conditions. Until recently, the main relevant medical professional organisations, the Australian Medical Association and the Royal Australian College of General Practitioners, have been opposed to capitation payment as an alternative to fee-for-service (Hunter, 1980; Gillespie, 1991; Royal Australian College of General Practitioners, 2015). 
Table 1. Reforms to Medicare Benefits Scheme (MBS) items for general practice, Australia, 1998-2016

\begin{tabular}{|c|c|c|}
\hline Years & Reform & Policy context/objective \\
\hline 1999 & Enhanced primary care programme & $\begin{array}{l}\text { Encourage multidisciplinary management of people } \\
\text { with chronic and complex needs through specific } \\
\text { payments to GPs for case conferencing and care } \\
\text { planning }\end{array}$ \\
\hline 1999 & Practice incentives programme & $\begin{array}{l}\text { Link extra payments to quality outcomes in specified } \\
\text { areas, such as asthma and cervical cancer }\end{array}$ \\
\hline 1999 & $\begin{array}{l}\text { Older Person's Health Assessment (annual } \\
\text { health assessments for people aged } 75 \text { and } \\
\text { over) }\end{array}$ & $\begin{array}{l}\text { Ensure early identification of health problems, } \\
\text { support early intervention and build opportunities } \\
\text { for prevention (e.g. reducing falls) }\end{array}$ \\
\hline 2001 & ' $3+$ ’'Asthma visit management plan & $\begin{array}{l}\text { Encourage GPs to provide best practice treatment } \\
\text { and management of patients with asthma }\end{array}$ \\
\hline 2004 & $\begin{array}{l}\text { 'Strengthening Medicare' (access to some } \\
\text { allied health services under the MBS) }\end{array}$ & $\begin{array}{l}\text { Encourage multidisciplinary care and referrals by } \\
\text { GP to allied health professionals for patients with } \\
\text { chronic disease }\end{array}$ \\
\hline 2005 & New chronic disease management items & $\begin{array}{l}\text { Replace the } 1999 \text { enhanced primary care programme } \\
\text { items; GPs with assistance of practice nurses can } \\
\text { undertake care planning and review services for } \\
\text { patients with chronic disease }\end{array}$ \\
\hline 2006 & $\begin{array}{l}\text { Australian better health initiative new } \\
\text { medicare items }\end{array}$ & $\begin{array}{l}\text { Encourage focus on prevention through well person's } \\
\text { health check for patients } 45+\text { with one or more } \\
\text { health risks }\end{array}$ \\
\hline 2016 & Health care homes trial & $\begin{array}{l}\text { Introduce programme of 'health care homes', to pilot } \\
\text { capitation payment }\end{array}$ \\
\hline
\end{tabular}

Source: Updated from Duckett and Willcox (2015).

The government's response to meeting chronic care needs has been a proliferation of new, largely item-based additions to the MBS, but no overarching strategic vision or end point for the future of general practice (Beilby, 2007). The Medicare payment rules for these items inhibit both innovation in the way practices manage chronic disease (Robson et al., 2014) and 'the links between different services at the local level' (Fine, 1999).

Even though this innovation has been a second-best solution because of the political difficulties of initiating wider capitation arrangements, each of these item-based additions is innovative. Table 1 identifies some of the major changes to the funding of general practice over the last two decades.

These initiatives have rarely been evaluated in terms of their impact on outcomes, with evaluations often simply focussing on process measures such as provider acceptability (Blakeman et al., 2001; Harris et al., 2002; Zwar et al., 2005; Rhee et al., 2012), uptake (Price et al., 2002; Wilkinson et al., 2002a; Wilkinson et al., 2002b, 2003; Hamirudin et al., 2015) and impact on allied health services (Cant and Aroni, 2007; Foster et al., 2008; Menz, 2009; Haines et al., 2010). The few outcome evaluations have been mildly positive, showing that the introduction of the Enhanced Primary Care items was associated with 
improved diabetes care (Zwar et al., 2007); that a 45+ health check was associated with change in patient exercise patterns but not clinical measures (Amoroso et al., 2009); and that a falls prevention programme funded through use of the chronic disease management items reduced falls (Mackenzie and Clemson, 2014).

The Practice Incentives Program introduced a pay-for-performance (P4P) element into primary medical care funding. More accurately described as 'pay for process adherence', as would be expected from the very mixed international evaluations of P4P (Tanenbaum, 2009; Cromwell et al., 2011; de Bruin et al., 2011; Eijkenaar, 2012; Eijkenaar et al., 2013), the Australian P4P experience in primary care is also mixed (Scott et al., 2009; Scott et al., 2011; Greene, 2013).

One particularly important innovation was the 2004 initiative to provide coverage for allied health services, thus facilitating multidisciplinary care. The Medicare Chronic Disease Management items (Australia's Medicare billing unit) allow GPs to refer selected patients to eligible allied health professionals, with patients able to claim Medicare rebates for a maximum of five allied health services annually. These services are only accessible for patients with a chronic disease whose GP has prepared a management plan and initiated team care arrangements. Allied health services can be provided by registered private practitioners who fall within one of the 14 classes of eligible allied health professionals.

In 2015-2016 over six million allied health services were provided under the chronic disease management MBS items at a cost to Medicare of about A $\$ 330$ million (data extracted from http://medicarestatistics.humanservices.gov.au/ statistics/mbs_item.jsp). About three-quarters of allied health services claimed under Medicare are for podiatry ( $45 \%$ of allied health services) and physiotherapy $(31 \%)$. There is fairly limited use of most of the other 12 categories of allied health services eligible for Medicare funding.

In common with many other countries (Tsiachristas et al., 2013; Struckmann et al., 2016), Australia's main response to using financial incentives to improve care continuity has been a pay-for-coordination strategy. Despite this, care coordination remains a critical issue for the health care system, causing problems with consistency of information provision and quality of care (Schoen et al., 2011). In 2016, Australians with chronic conditions were more likely to have experienced problems with care coordination than their counterparts in comparable countries (the United Kingdom, United States, New Zealand, Canada, France, Germany, the Netherlands, Norway, Sweden and Switzerland); specifically Australians with chronic conditions were less likely to have discussed their main goals and care priorities with a health professional, and less likely to have discussed treatment options and side effects (Osborn et al., 2016). More than $\$ 1$ billion dollars a year is spent on pay-for-coordination or $\mathrm{P} 4 \mathrm{P}$ payments but still a high proportion of patients with chronic disease do not receive recommended best practice care (Swerissen and Duckett, 2016). 
The 2016-2017 'health care homes trial' is the latest attempt to update the Medicare payment arrangements to encourage better care for people with chronic conditions (Dwyer and Duckett, 2016; Gunn, 2016). The trial is relatively small with only 65,000 patients across 200 practices (Department of Health, 2016) and is more designed as a minimalist toe-in-the-water rather than transformational change. It does not provide the essential foundations for the primary care reforms which are necessary (Swerissen and Duckett, 2017), nor address recognised problems of voluntary enrolment (Glazier et al., 2012; Kiran et al., 2016). It involves voluntary enrolment of patients and capitation payments for these patients. Despite its limitations, it represents the beginning of a process of change which could provide a basis for more systemic change over time by allaying the medical profession's fears of funding reform and aversion to capitation.

The lessons for Canada from Australia's MBS system are mixed. A number of provinces have introduced 'alternative payment plans' for family physicians, and Canada has rightly been described as a leader in such developments (Wranik and Durier-Copp, 2009), with mixed results in terms of the benefit of the alternative models compared to fee-for-service (Hutchison and Glazier, 2013; Rudoler et al., 2015; Howard et al., 2016; Lavergne et al., 2016; Laberge et al., 2017).

More change for primary care payment is on the way in Canada, at least in Ontario (Marchildon and Hutchison, 2016), and Canadian provinces could perhaps learn from Australia's blended payment model. In particular, grafting new incentives onto the fee-for-service system has been achieved with the medical profession's support. However, these changes have been incremental, poorly planned and do not provide a coherent basis for a primary care system well adapted to emerging needs. Notwithstanding that, there is still potential to assess each of the innovations in terms of their ability to supplement existing Canadian approaches to addressing the challenges of the epidemiological transition to greater prevalence of chronic conditions. The first lesson is about the strategy of grafting new incentives onto a fee-for-service system, not the precise way Australia has implemented these changes. The second lesson is about how Australia has extended access to allied health services such as physical therapy - traditionally not part of Medicare in Canada - by means of integration into a Medicare framework.

\section{Support for the elderly}

Commonwealth support for aged care services, more recently reformulated as support for people in need (through direct grants which can then be used by recipients to purchase services from any provider) has a long tradition, commencing early in the 20th century and is associated with support for people in receipt of Commonwealth pensions. It was stimulated as part of post Second World War reconstruction, but was expanded through subsidies for church and charitable organisations to provide aged care accommodation by the Liberal 
(conservative) government in the mid-1950s (Kewley, 1973; Dixon, 1977; Jeon and Kendig, 2017). Over the last 40 years, policy has shifted towards emphasising support to keep frail older people in the community rather than providing support to the service provider (Gibson, 1998, 1996; Australian Institute of Health and Welfare, 2014), with the most recent changes being the result of a comprehensive review of current and future challenges for the aged care system (Productivity Commission, 2011; Jeon and Kendig, 2017). This is the area where Australia has lessons for Canada.

The Australian aged care arrangements are efficient (especially in terms of reducing demand for high cost residential care) and equitable (available to all people, but with greater support to those with fewer assets and lower income). The existing aged support arrangements involve a coordinated mix of residential support and support for home care services.

\section{Community or home-based care}

The basis for all aged care assistance is assessment of need. As part of the 'My Aged Care' portal, Commonwealth government-funded Regional Assessment Services assess the support needs of older people using standardised assessment instruments independently of service providers. If a person's needs are able to be met in the home, the 'Commonwealth Home Support Program' provides assistance within three broad service sub-programmes:

- Community and home support provides entry-level services to support older people to live independently at home and in the community, for example, meals, domestic assistance and transport.

- Care relationships and carer support is available to support and maintain care relationships between older people and their carers.

- Assistance with care and housing supports vulnerable clients to remain in the community through accessing appropriate, sustainable and affordable housing and linking them to community care and other support services.

Funding under the Commonwealth Home Support Program is structured into 'service groups' which are designed to achieve common goals or outcomes: increased independence; nutrition; social participation; assistance at home; access to the community; and care relationships. Consumers have a choice of care providers from providers participating in the scheme who have been allocated funding by the Commonwealth government - across all the relevant sub-programmes.

There is a standard national fee schedule, with consumers being expected to contribute a 'basic daily fee of up to 17.5 per cent of the pension', with an income-tested amount above that of up to $\mathrm{A} \$ 25,000-\mathrm{A} \$ 40,000$ depending on marital status and living arrangements (the range quoted is single compared with couple; see http://www.myagedcare.gov.au/costs/help-home-costs-explained, accessed 22 December 2016). 


\section{Residential and substitute care}

Older people who require access to more intensive support than is available through the Commonwealth Home Support Program face further assessment to determine their eligibility to access either community-based or residential aged care services. Subject to this assessment, people who require a higher level of support than is available in the Commonwealth Home Support Programs, but do not need to move into a residential aged care facility, can be allocated a 'home care package'. Packages range in value from a base subsidy of $\$ 22.04$ per week to $\$ 133.09$ per week, with supplements paid for some attributes of the patient (e.g. with dementia) or in rural and remote locations (see https://agedcare.health. gov.au/funding/aged-care-subsidies-and-supplements/schedule-of-subsidies-andsupplements, accessed 4 January 2017).

Since July 2012, all new Home Care Packages have been provided as 'Consumer-directed Care' packages which give consumers a personalised budget for them to purchase their desired mix of services. People in receipt of Home Care Packages pay the same fees as under the Commonwealth Home Support Program.

People with higher level needs are supported to live in residential aged care where they receive personal care. There are two major sources of funding to support people in residential facilities. These are:

- A Commonwealth subsidy, which varies with the resident's dependency and need for care; and

- A resident payment, the latter in part recognising that residential facilities provide food and shelter that residents would need to pay for wherever they lived.

The care cost subsidies are based on the resident's needs as measured using the Aged Care Funding Instrument which involves an appraisal of the resident's 'usual care needs' across three domains: activities of daily living (such as mobility and continence); behaviour (such as cognitive skills and depression); and complex health care (including use of medication).

To encourage residential care facilities to give places to residents who cannot meet their own accommodation costs, the Commonwealth also pays supplements to facilities based on the share of concessional residents, although the level of the payment may be insufficient to ensure appropriate access (Gargett, 2010).

\section{Lessons for Canada}

As people age, they become frailer and their informal social supports (often through partners, husbands, wives) become more fragile. Care needs increase in fits and starts, often as a result of a slow continuous functional decline, sometimes because of acute events (strokes, falls). The pathways to care are quite different depending on the nature of the underlying disablement, with people with dementia or who have had a stroke having quite different patterns compared with people with other conditions (Karmel et al., 2012). Design of aged care funding 
arrangements is complex, as it has to be designed with interactions with both income support policy and housing ownership in mind (Ong, 2016).

The Australian system is strong on providing access, particularly to communitybased care. Median waiting times between assessment and admission to care in 2014-2015 were 84 days for residential care and 73 days for home care. Further, one-quarter of people were admitted to residential care within 1 month, and a third accessed home care within that period [Steering Committee for the Review of Commonwealth/State Service Provision (SCRCSSP), 2017], with some of the delay presumably to organise financing and other arrangements. However, regulation of quality of residential care has demonstrable weaknesses, and Canadian provinces could only learn from Australia's failures in this area, not its success (Hamilton and Menezes, 2011; Baldwin et al., 2015a, 2015b).

In contrast to the comprehensiveness and universality of Australia's aged care support, the Canadian service system, as currently structured, is poorly suited to respond, and is characterised by discontinuities: discontinuities between hospitals and services outside those walls, between home care and residential care, and between 'health' and 'social' care. These discontinuities impact on both individuals and the system as a whole. For the individual, they may not get the service that is most appropriate for them. For the system, it may lead to inefficiency in that people might remain in hospital, for example, when they would be better cared for in another location (Manzano-Santaella, 2010a, 2010b).

As Hirdes pointed out:

Canada's universal, publicly funded health care system has not been designed in a way that established a uniform national approach to long-term care. Instead, the needs of the frail elderly are addressed through a policy mosaic that results in inequalities in access to services and differential burdens of care on family members. Moreover, the lack of a standardized health information system has made it difficult to compare the experiences of users of long-term care systems from province to province (2001).

This is in contrast to Australia where there is a universal, national programme for aged care, which emphasises home care and support. Expansion of home care in Canada was supported by the two national inquiries into health care conducted in the last 20 years [Senate. Standing Committee on Social Affairs Science Technology (Chair: Senator Michael Kirby), 2002; Commission on the Future of Health Care in Canada (Chair: Roy Romanow), 2002], with the Romanow Commission referring to home care as 'the next essential service' [Commission on the Future of Health Care in Canada (Chair: Roy Romanow), 2002: 171]. Australia can provide useful lessons on the means to organise such an expansion.

\section{Hospital efficiency}

Unlike Canada, Australia has a mixed system of hospital provision. All Australians are eligible to receive treatment in public hospitals - hospitals generally owned by state 
governments but operated by quasi-independent boards of directors appointed by the State government. Some states do not have independent boards of hospitals; there are also a handful of hospitals run by Roman Catholic organisations - formerly religious orders of nuns - which operate as public hospitals (Gleeson, 1989). Public hospital funding is determined by state governments, with substantial subsidies (around $40 \%$ of funding) from the Commonwealth government, but paid via the states (Duckett, 2015). Private hospitals are owned by a mix of for profit and not-for-profit organisations, charging patients for accommodation (Duckett and Willcox, 2015).

Australia has been an international pioneer in driving efficiency in its hospital services, principally through the introduction of activity-based funding (or 'casemix' funding as it was originally termed). Victoria adopted activity-based funding as the basis of paying for public hospital inpatient services in 1993 (Duckett, 1995), and its scope has been expanded to other aspects of public hospital care since then. A 2011 national agreement has led to activity-based funding being adopted in larger states and nationally for determining adjustments to the flow of funds between the Commonwealth and states (Council of Australian Governments, 2016, 2011).

An important piece of national infrastructure is the Independent Hospital Pricing Authority, which is indeed independent as its name implies: the Commonwealth government chooses the Chair, the states and territories the Deputy Chair, and all other members are agreed through the Council of Australian Governments.

Typically, the key features characterising activity-based payment used by states in payment models for public hospitals have comprised the following:

- Standard prices: Most states have adopted the 'National Efficient Price' determined by the Independent Hospital Pricing Authority used for determining the Commonwealth payments to states (Independent Hospital Pricing Authority, 2015).

- Use of payment relativities (termed 'payment weights') to determine relative prices across diagnosis related groups (DRGs): Payment weights are calculated by the Independent Hospital Pricing Authority from cost data submitted by states.

- Capping of expenditure: Unlike the private sector, state government spending on public hospitals is capped, usually achieved either through explicit volume caps (no payment for services above a negotiated or target level) or by declining marginal payment for additional volume. Commonwealth government funding of the costs of activity growth is also capped at an arbitrary $6.5 \%$ per annum, although this cap is unlikely to be breached given recent levels of cost and activity growth.

Since 2014/2015 Commonwealth payments to states are adjusted in line with changes in activity and costs. Importantly, this activity adjustment is paid at the 'National Efficient Price' as determined by the Independent Hospital Pricing Authority. 
The 2016 Agreement on hospital funding introduced a new element to the funding formula: payment for quality (Council of Australian Governments, 2016). The Independent Hospital Pricing Authority has been directed to incorporate consideration of specified adverse events (including a list of agreed hospital acquired conditions), ineffective interventions, and readmissions into their pricing structure. The Authority has advanced a number of ways in which that could be done for phased implementation from July 2017 (Independent Hospital Pricing Authority, 2016).

Australia's hospital system is more efficient than Canada's (Varabyova and Schreyögg, 2013) and there are two clear lessons for Canada in the Australian experience of driving improvements in hospital efficiency. First, there has been the very clear acceptance that there is room to improve the efficiency of hospital care, and that this is best done through paying hospitals on the basis of their activity, not their history, negotiated 'global budgets' or other methods (Duckett et al., 2014). Second, Australian governments have negotiated an agreement which means that the Commonwealth and states share the costs of growth in hospital demand, but the formula includes an incentive for efficiency, by only funding growth using an 'efficient price'.

\section{Cautionary tales: the problems of mixed public and private funding}

All is not rosy in Australia, and there are cautionary tales about Australian health polices which can inform contemporary Canadian policy debates. In particular, the effects of Australia's high level of private funding and provision can provide a warning signal to Canada about the potential consequences of increased private funding in the context of the current Charter challenge being litigated in the British Columbia Cambie case (Costain, 2017).

\section{Out-of-pocket costs}

Compared with many countries, Australian consumers contribute a large proportion of health care costs through fees: almost one-fifth of all health care spending. Australia is ranked in the middle of the Organisation for Economic Co-Operation and Development for the proportion of health costs paid for with out-of-pocket fees. Compared with 17 other wealthy countries, however, Australia has the third highest reliance on these payments. Only Switzerland and Belgium outstrip Australia, and rates are far lower in the United Kingdom, Canada and New Zealand. The amount Australians pay as a proportion of their household expenditure is also relatively high (Duckett and Breadon, 2014).

An Australian Bureau of Statistics survey found that almost one in 20 of people need to see a GP but do not go because of cost, with the rate higher for females $(5.2 \%)$ than males $(2.8 \%)$. The proportion is $8 \%$ for specialists and $19 \%$ for dentists (Australian Bureau of Statistics, 2016). According to data from the 
Commonwealth Fund's international health policy survey, Australia (at 14\%) and Canada (at 16\%) had similar proportions of respondents reporting that they 'had any cost-related access problem to medical care in past year' (Osborn et al., 2016).

Of the almost A $\$ 30$ billion spent by households on health care in 2014-2015, about one-third was for medications not covered by the PBS (including vitamins and supplements), and 5\% for PBS medications (Australian Institute of Health and Welfare, 2016b). Other large components were dental care (about 20\% of household health care spending) and aids and appliances (about 10\%). Poorer families spend a higher proportion of their income (but a lower absolute amount) than wealthier families.

Although only a small proportion of household health expenditure - around $2 \%-$ is for family physician visits, the distribution of this is uneven (e.g. higher co-payments in rural areas) and, as indicated above, these out-of-pocket costs create a barrier to access for some.

There is no regulation of patient fees in Australia, nor are doctors who 'extra-bill' required to opt-out of public funding. As a result, patient charges are at the whim of the individual practice with medical practitioners applying their own assessment of whether patients will be charged any fee and, if charged, what level of payment will be required. There is thus considerable variation in fees charged (Freed and Allen, 2017; Hua et al., 2017; Johar et al., 2017).

Australia's high level of reliance on out-of-pocket payments is an area of weakness on the equity criterion. Out-of-pocket payments are thus one area where Canada can learn from Australia, but this is something that Canada should avoid rather than emulate.

\section{Private hospital care and private health insurance}

In addition to out-of-pocket contributions, there is a significant role for private funding in Australia - just under $9 \%$ of all health care funding is mediated through private health insurance (Australian Institute of Health and Welfare, 2016b). Private health insurance is heavily subsidised by the Commonwealth government through rebates to the insured population which cover about $25 \%$ of the cost of insurance policies, and insurance is further encouraged by a complex array of carrots and sticks (Hall et al., 1999; Palangkaraya and Yong, 2005; Kay, 2017; Kettlewell et al., 2018; McDonald and Duckett, 2017). In Canada, private health insurance complements public provision in that there is no overlap in coverage. In contrast, private health insurance in Australia facilitates private hospital care (Eldridge et al., 2017) and provides insurance for the same services which might also be provided, for most patients without charge, in public hospitals. In addition to covering private hospital care, private health insurance also provides rebates against dental fees and allied health services.

Almost half the population is covered by private health insurance, although most have products with high levels of deductibles and exclusion clauses. 
In addition to this private funding, Australia has a strong private hospital sector, with private health insurance responsible for almost half of that sector's revenue and government subsidies through health insurance accounting for a further one-fifth of revenue (totalling 68\% of private hospital revenue).

Private hospitals primarily specialise in elective procedures, which account for over $80 \%$ of their activity (Australian Institute of Health and Welfare, 2016a). Almost $60 \%$ of all elective admissions are admitted to private hospitals, in contrast only $8 \%$ of emergency admissions are admitted to private hospitals.

Private hospitals admit patients of lower levels of acuity (Table 2 shows data about orthopaedic procedures showing for both hip and knee replacements), as well as higher proportions of cases in the less complex Diagnosis-Related Group. They also tend to refer out more complex patients and receive referrals of less complex patients from public hospitals (Cheng et al., 2015).

Table 2 shows that private hospitals admit proportionately more of the simpler elective hip and knee replacements (for hips, around 58\% for the simpler around 67\% for the simpler - without catastrophic complications or comorbidities; around $42 \%$ for more complex) than expected given the prevalence of private health insurance in Australia (around $47 \%$ ). In contrast, for three of the four arthroplasty groups, private hospitals admit a much smaller proportion of emergency admissions. Patients in private hospitals tend to stay longer than patients in public hospitals, suggesting they may be less efficient (all differences for arthroplasty groups are statistically significant).

Medical practitioners are able to work in both the public and private sectors, with most working in both (Cheng et al., 2013). A key determinant of whether medical practitioners choose to work in the public or private sectors is remuneration. In Australia, remuneration per hour is greater in the private sector than it is in the public sector. This differential remuneration creates a theoretical incentive to work in the private sector, and this is borne out empirically: Cheng and Vahid (2011) have shown that an increase in private earnings is more than offset by any reduction in earnings from the public sector.

It is possible that one consequence of this combination of incentives, insofar as it promotes private activity over public activity, is greater waiting times in the public system. Some supporting evidence for this hypothesis can be seen in that median waiting times for procedures are lower when the public patient share of activity for that specialty is greater (Duckett, 2005).

However, attributing causation to this result is problematic, in part because it is difficult to determine the direction of causation. There are two competing hypotheses. One suggests that doctors create waiting lists in the public sector to increase demand for their work in the private sector, for which they earn more. The other suggests that the supply imbalance in the public sector has its root in under-resourcing of the sector, which drives activity towards the private sector. There is no substantial empirical evidence that sheds light on which of these hypotheses is more credible. Evidence of the impact of private vs public sector earnings on waiting times is therefore inconclusive. 
Table 2. Number and length of stay for selected diagnosis-related groups, Australia, 2010-2011

\begin{tabular}{|c|c|c|c|c|c|c|c|}
\hline & \multicolumn{3}{|c|}{ Public } & \multicolumn{3}{|c|}{ Private } & \multirow[b]{2}{*}{ Total } \\
\hline & Emergency & Elective & $\begin{array}{l}\text { Total } \\
\text { public }\end{array}$ & Emergency & Elective & $\begin{array}{l}\text { Total } \\
\text { private }\end{array}$ & \\
\hline \multicolumn{8}{|l|}{$103 \mathrm{~A}$} \\
\hline \multicolumn{8}{|c|}{ Hip replacement with catastrophic CC } \\
\hline Number of discharges & 916 & 1042 & 1958 & 163 & 1241 & 1404 & 3362 \\
\hline Average length of stay & 15.9 & 9.5 & 12.5 & 17.7 & 10.2 & 11.1 & 11.9 \\
\hline Median length of stay & 14 & 8 & 10 & 15 & 8 & 8 & 9 \\
\hline \multicolumn{8}{|l|}{$103 \mathrm{~B}$} \\
\hline \multicolumn{8}{|c|}{ Hip replacement without catastrophic CC } \\
\hline Number of discharges & 4336 & 7342 & 11,678 & 876 & 15,360 & 16,236 & 27,914 \\
\hline Average length of stay & 9.6 & 6.0 & 7.3 & 11.0 & 6.4 & 6.7 & 6.9 \\
\hline Median length of stay & 8 & 5 & 6 & 9 & 6 & 6 & 6 \\
\hline \multicolumn{8}{|l|}{$104 \mathrm{~A}$} \\
\hline \multicolumn{8}{|c|}{ Knee replacement with catastrophic CC } \\
\hline Number of discharges & 51 & 1183 & 1234 & 20 & 1680 & 1700 & 2934 \\
\hline Average length of stay & 16.8 & 10.1 & 10.3 & 20.5 & 10.1 & 10.2 & 10.3 \\
\hline Median length of stay & 14 & 8 & 8 & 22 & 9 & 9 & 9 \\
\hline \multicolumn{8}{|l|}{ 104B } \\
\hline \multicolumn{8}{|c|}{ Knee replacement without catastrophic CC } \\
\hline Number of discharges & 72 & 11,521 & 11,593 & 97 & 23,066 & 23,163 & 34,756 \\
\hline Average length of stay & 8.1 & 5.9 & 5.9 & 7.9 & 6.4 & 6.4 & 6.2 \\
\hline Median length of stay & 6 & 5 & 5 & 7 & 6 & 6 & 6 \\
\hline
\end{tabular}

Note: $\mathrm{CC}=$ complications or comorbidities.

Source: Author's analysis.

Private provision may not undermine Canada's Medicare if the provision is under subcontract to the public funder as a complement and is not an alternative. For example, a number of Canadian provinces have experience with both not-for-profit hospitals (especially run by Roman Catholic religious groups) and for-profit specialist providers functioning within the Medicare framework. In contrast, private funding certainly has its dangers. As the Australian experience shows, private funding brings the risk of potential cream-skimming and differential access, and does little to reduce pressure on waiting times. There is also little evidence that private provision improves efficiency through competitive pressure, and may lead to increased prices (Buckley et al., 2012).

\section{Conclusion}

Australia's mixed public-private, Commonwealth-state health system has both positive and negative lessons for Canada. The common heritage of the dominant culture has led to many similarities in system design (Crichton, 1998); but it is the 
differences which can lead to lessons from one country to the other. First, Australia has expanded provision in two key areas where there is quite inadequate provision across Canada: access to pharmaceuticals and programmes to support older people in need of home-based or residential care. Australia's pharmaceutical strategy has resulted in lower prices being paid for medications compared with Canada and may provide evidence to those who claim a Canadian 'Pharmacare' may be able to be at least partly funded by better drug prices.

Australia might also provide lessons about driving efficiency in hospital provision and in adapting a fee-for-service system to meet the needs of people with chronic conditions.

There are also lessons about what to avoid. Australia's high level of outof-pocket costs and mixed private funding arrangements are associated with both differential access and barriers to seeking care.

\section{Acknowledgement}

Valuable comments were received from reviewers and participants in the AMS 80th Anniversary Symposium. Remaining errors are the author's.

\section{References}

Acosta, A., A. Ciapponi, M. Aaserud, V. Vietto, A. Austvoll-Dahlgren, J. P. Kösters, C. Vacca, M. Machado, D. H. Diaz Ayala and A. D. Oxman (2014), 'Pharmaceutical policies: effects of reference pricing, other pricing, and purchasing policies', The Cochrane Database of Systematic Reviews, 2014(10): 1-116.

Amoroso, C., M. F. Harris, A. Ampt, R. A. Laws, S. McKenzie, A. M. Williams, U. W. Jayasinghe, N. A. Zwar and G. P. Davies (2009), 'The 45 year old health check: feasibility and impact on practices and patient behaviour', Australian Family Physician, 38(5): 358.

Anderson, I., B. Robson, M. Connolly, F. Al-Yaman, E. Bjertness, A. King, M. Tynan, R. Madden, A. Bang, C. E. A. Coimbra Jr, M. A. Pesantes, H. Amigo, S. Andronov, B. Armien, D. A. Obando, P. Axelsson, Z. S. Bhatti, Z. A. Bhutta, P. Bjerregaard, M. B. Bjertness, R. Briceno-Leon, A. R. Broderstad, P. Bustos, V. Chongsuvivatwong, J. Chu, Deji, J. Gouda, R. Harikumar, T. T. Htay, A. S. Htet, C. Izugbara, M. Kamaka, M. King, M. R. Kodavanti, M. Lara, A. Laxmaiah, C. Lema, A. M. L. Taborda, T. Liabsuetrakul, A. Lobanov, M. Melhus, I. Meshram, J. J. Miranda, T. T. Mu, B. Nagalla, A. Nimmathota, A. I. Popov, A. M. P. Poveda, F. Ram, H. Reich, R. V. Santos, A. A. Sein, C. Shekhar, L. Y. Sherpa, P. Skold, S. Tano, A. Tanywe, C. Ugwu, F. Ugwu, P. Vapattanawong, X. Wan, J. R. Welch, G. Yang, Z. Yang and L. Yap (2016), 'Indigenous and tribal peoples' health (The Lancet-Lowitja Institute Global Collaboration): a population study', The Lancet, 388(10040): 131-157.

Australian Bureau of Statistics (2016), Patient Experiences in Australia: Summary of Findings, 2015-16 (4839.0), Canberra: ABS.

Australian Institute of Health and Welfare (2011), 'Comparing life expectancy of indigenous people in Australia, New Zealand, Canada and the United States - conceptual, methodological and data issues'. Cat. no. IHW 47, Australian Institute of Health and Welfare, Canberra. 
Australian Institute of Health and Welfare (2014), 'Patterns in use of aged care 2002-03 to 2010-11'. Data Linkage Series. Cat no. CSI 20, AIHW, Canberra.

Australian Institute of Health and Welfare (2016a), 'Admitted patient care 2014-15: Australian hospital statistics'. Cat no. HSE 172, AIHW, Canberra.

Australian Institute of Health and Welfare (2016b), 'Health expenditure Australia 2014-5'. Cat no. HWE 67, AIHW, Canberra.

Baldwin, R., L. Chenoweth and M. D. Rama (2015a), 'Residential aged care policy in Australia - are we learning from evidence?', Australian Journal of Public Administration, 74(2): $128-141$.

Baldwin, R., L. Chenoweth, M. D. Rama and Z. Liu (2015b), 'Quality failures in residential aged care in Australia: the relationship between structural factors and regulation imposed sanctions', Australasian Journal on Ageing, 34(4): E7-E12.

Beilby, J. (2007), 'Primary care reform using a layered approach to the Medicare Benefits Scheme: unpredictable and unmeasured', Medical Journal of Australia, 187(2): 69-71.

Beilby, J., S. Wutzke, J. Bowman, J. Mackson and L. Weekes (2006), 'Evaluation of a national quality use of medicines service in Australia: an evolving model', Journal of Evalutation in Clinical Practice, 12(2): 202-217.

Birkett, D. J., A. S. Mitchell and P. McManus (2001), 'A cost-effectiveness approach to drug subsidy and pricing in Australia', Health Affairs, 20(3): 104-114.

Blakeman, T. M., M. F. Harris, E. J. Comino and N. A. Zwar (2001), 'Evaluating general practitioners' views about the implementation of the Enhanced Primary Care Medicare items', Medical Journal of Australia, 175: 95-98.

Boothe, K. (2012), 'How the pace of change affects the scope of reform: pharmaceutical insurance in Canada, Australia, and the United Kingdom', Journal of Health Politics, Policy and Law, 37(5): 779-814.

Buckley, N. J., K. Cuff, J. Hurley, L. McLeod, S. Mestelman and D. Cameron (2012), 'An experimental investigation of mixed systems of public and private health care finance', Journal of Economic Behavior \& Organization, 84(3): 713-729.

Bulfone, L., S. Younie and R. Carter (2009), 'Health technology assessment: reflections from the Antipodes', Value in Health, 12(Supplement 2): S28-S38.

Cant, R. and R. Aroni (2007), 'Melbourne dietitians' experience of Medicare policy on allied health services (strengthening Medicare; enhanced primary care) in the first 12 months', Nutrition \& Dietetics, 64(1): 43-49.

Cheng, T. C. and F. Vahid (2011), 'Demand for hospital care and private health insurance in a mixed public-private system: empirical evidence using a simultaneous equation modeling approach', Melbourne Institute of Applied Economic and Social Research, University of Melbourne, Parkville, VIC.

Cheng, T. C., C. M. Joyce and A. Scott (2013), 'An empirical analysis of public and private medical practice in Australia', Health Policy, 111(1): 43-51.

Cheng, T. C., J. P. Haisken-DeNew and J. Yong (2015), 'Cream skimming and hospital transfers in a mixed public-private system', Social Science \& Medicine, 132: 156-164.

Clement, F. M., A. Harris, J. J. Li, K. Yong, K. M. Lee and B. J. Manns (2009), 'Using Effectiveness and cost-effectiveness to make drug coverage decisions: a comparison of Britain, Australia, and Canada', JAMA, 302(13): 1437-1443.

Coleman, M. P., D. Forman, H. Bryant, J. Butler, B. Rachet, C. Maringe, U. Nur, E. Tracey, M. Coory, J. Hatcher, C. E. McGahan, D. Turner, L. Marrett, M. L. Gjerstorff, T. B. Johannesen, J. Adolfsson, M. Lambe, G. Lawrence, D. Meechan, E. J. Morris, 
R. Middleton, J. Steward and M. A. Richards (2011), 'Cancer survival in Australia, Canada, Denmark, Norway, Sweden, and the UK, 1995-2007 (the International Cancer Benchmarking Partnership): an analysis of population-based cancer registry data', The Lancet, 377(9760): 127-138.

Commission on the Future of Health Care in Canada (Chair: Roy Romanow) (2002), 'Building on values: the future of health care in Canada'. Commission on the Future of Health Care in Canada.

Costain, K. (2017), 'Decontextualized rights: concerns regarding the Bedford section 7 framework in the health care context of the Cambie surgery center trial', Appeal: Review of Current Law \& Law Reform, 22: 3-23.

Council of Australian Governments (2011), National Health Reform Agreement, Canberra: COAG.

Council of Australian Governments (2016), Heads of Agreement Between the Commonwealth and the States and Territories on Public Hospital Funding, Canberra: COAG.

Crichton, A. (1995), 'Health care in Canada and Australia: the development of a comparative analytical framework', Australian-Canadian Studies, 13(2): 59-71.

Crichton, A. (1998), Children of a Common Mother: A Comparative Analysis of the Development of the Australian and Canadian Health Care Systems to 1995, Australian Studies in Health Service Administration, Volume 83, Kensington: School of Health Services Management, University of New South Wales.

Cromwell, J., M. G. Trisolini, G. C. Pope, J. B. Mitchell and L. M. Greenwald (eds) (2011), Pay for Performance in Health Care: Methods and Approaches, Research Triangle Park, NC: RTI Press.

de Bruin, S. R., A. B. Caroline and J. N. Struijs (2011), 'Pay-for-performance in disease management: a systematic review of the literature', BMC Health Services Research, 11(1): 272.

Department of Health (2016), Health Care Homes - Patient-Centred, Co-Ordinated, Flexible: Information Booklet, Canberra: The Department of Health.

Dixon, J. (1977), Australia's Policy Towards the Aged: 1890-1972, Canberra Series in Administrative Studies, Volume 3, Canberra: Canberra College of Advanced Education.

Donelan, K., R. J. Blendon, C. Schoen, K. Davis and K. Binns (1999), 'The cost of health system change: public discontent in five nations', Health Affairs, 18(3): 206-216.

Duckett, S. (1983), 'Recent developments in Canadian health services: lessons for Australia', Australian Quarterly, 55(1): 54-65.

Duckett, S. (1995), 'Hospital payment arrangements to encourage efficiency: the case of Victoria, Australia', Health Policy, 34: 113-134.

Duckett, S. (2005), 'Private care and public waiting', Australian Health Review, 29(1): 87-93.

Duckett, S. (2014), 'Australia', in K. Fierlbeck and H. A. Palley (eds), Comparative Health Care Federalism: Competition and Collaboration in Multistate Systems, Farnham, England: Ashgate, 123-138.

Duckett, S. (2015), 'Australia', in G. P. Marchildon and L. Di Matteo (eds), Bending the Cost Curve in Health Care, Toronto, ON: University of Toronto Press, 381-410.

Duckett, S. (2017), 'Don't be fooled, the Medicare Guarantee Fund provides no real guarantee'. The Conversation 12 May, 2017, https://theconversation.com/dont-be-fooled-themedicare-guarantee-fund-provides-no-real-guarantee-77555 [12 December 2017].

Duckett, S. and P. Breadon (2014), 'Out-of-Pocket Costs: Hitting the Most Vulnerable Hardest', Grattan Institute submission to the Senate Standing Committee on Community Affairs Inquiry into the out-of-pocket costs in Australian healthcare, Grattan Institute, Melbourne, VIC. 
Duckett, S. and S. Willcox (2015), The Australian Health Care System, Melbourne: Oxford University Press.

Duckett, S. and P. Banerjee (2017), Pricing Prescriptions: Savings From Benchmarking Internationally and With Other Drugs, Melbourne, VIC: Grattan Institute.

Duckett, S., P. Breadon, B. Weidmann and I. Nicola (2014), Controlling Costly Care: A Billion-Dollar Hospital Opportunity, Melbourne, VIC: Grattan Institute.

Dwyer, J. M. and S. J. Duckett (2016), 'Restructuring primary health care in Australia', The Medical Journal of Australia, 205(10): 435-436.

Dwyer, J. M., J. Lavoie, K. O’Donnell, U. Marlina and P. Sullivan (2011), 'Contracting for Indigenous health care: towards mutual accountability', Australian Journal of Public Administration, 70(1): 34-46.

Eijkenaar, F. (2012), 'Pay for performance in health care', Medical Care Research and Review, 69(3): 251-276.

Eijkenaar, F., M. Emmert, M. Scheppach and O. Schöffski (2013), 'Effects of pay for performance in health care: a systematic review of systematic reviews', Health Policy, 110(2-3): 115-130.

Eldridge, D. S., I. Onur and M. Velamuri (2017), 'The impact of private hospital insurance on the utilization of hospital care in Australia', Applied Economics, 49(1): 78-95.

Elson, S. (2009), 'Regionalization of health care from a political and structural perspective', Healthcare Management Forum, 22(1): 6-11.

Fine, M. (1999), 'Coordinating health, extended care, and community support services: reforming aged care in Australia', Journal of Aging \& Social Policy, 11(1): 67-90.

Foster, M. M., G. Mitchell, T. Haines, S. Tweedy, P. Cornwell and J. Fleming (2008), 'Does enhanced primary care enhance primary care? Policy-induced dilemmas for allied health professionals', Medical Journal of Australia, 188(1): 29-32.

Freed, G. L. and A. R. Allen (2017), 'Variation in outpatient consultant physician fees in Australia by specialty and state and territory', Medical Journal of Australia, 206(4): 176-180.

Gagnon, M.-A. (2010), 'The economic case for universal pharmacare: costs and benefits of publicly funded drug coverage for all Canadians Ottawa and Montreal', Canadian Centre for Policy Alternatives and Institut de recherche et d'informations socioéconomiques.

Gargett, S. (2010), 'The introduction of a targeted user-pays approach to funding high-level residential aged care in Australia: an empirical investigation of the impact on price', Health Economics, Policy and Law, 5(4): 481-508.

George, B., A. Harris and A. Mitchell (2001), 'Cost-effectiveness analysis and the consistency of decision making: evidence from pharmaceutical reimbursement in Australia (1991 to 1996)', PharmacoEconomics, 19(11): 1103-1109.

Gibson, D. (1996), 'Reforming aged care in Australia: change and consequence', Journal of Social Policy, 25(2): 157-179.

Gibson, D. (1998), Aged Care: Old Policies, New Problems, Cambridge: Cambridge University Press.

Gillespie, J. A. (1991), The Price of Health: Australian Governments and Medical Politics 1910-1960, Cambridge: Cambridge University Press.

Glazier, R. H., A. Kopp, S. E. Schultz, T. Kiran and D. A. Henry (2012), 'All the right intentions but few of the desired results: lessons on access to primary care from Ontario's patient enrolment models', Healthcare Quarterly, 15(3): 17-21. 
Gleeson, M. (1989), 'Organizational change in Australian Catholic hospitals'. PhD thesis, Kensington: University of New South Wales.

Greene, J. (2013), 'An examination of pay-for-performance in general practice in Australia', Health Services Research, 48(4): 1415-1432.

Gunn, J. (2016), 'Time for better chronic disease management in primary care'. The Conversation, 31 March, https://theconversation.com/time-for-policy-rethink-asfrequent-gp-attenders-account-for-41-of-costs-38966 [12 December 2017].

Haines, T. P., M. M. Foster, P. Cornwell, J. Fleming, S. Tweedy, A. Hart and G. Mitchell (2010), 'Impact of enhanced primary care on equitable access to and economic efficiency of allied health services: a qualitative investigation', Australian Health Review, 34(1): $30-35$.

Hall, J., R. De Abreu Lourenco and R. Viney (1999), 'Carrots and sticks - the fall and fall of private health insurance in Australia', Health Economics, 8(8): 653-660.

Hamilton, S. D. and F. M. Menezes (2011), 'Embedded incentives in the funding arrangements for residential aged care in Australia', Economic Papers, 30(3): 326-340.

Hamirudin, A. H., A. Ghosh, K. Charlton, A. Bonney and K. Walton (2015), 'Trends in uptake of the $75+$ health assessment in Australia: a decade of evaluation', Australian Journal of Primary Health, 21(4): 423-428.

Harris, M. F. and N. A. Zwar (2007), 'Care of patients with chronic disease: the challenge for general practice', Medical Journal of Australia, 187(2): 104-107.

Harris, M. F., T. M. Blakeman and N. A. Zwar (2002), 'Evaluating general practitioners' views on the enhanced primary care items for care planning and case conferencing. A one year follow up', Australian Family Physician, 31(6): 582.

Hirdes, J. P. (2001), 'Long-term care funding in Canada: a policy mosaic', Journal of Aging \& Social Policy, 13(2/3): 69-81.

House of Representatives. Standing Committee on Health and Ageing (2006), The Blame Game: Report on the Inquiry into Health Funding, Canberra: Commonwealth of Australia.

Howard, M., M. Chalifoux and P. Tanuseputro (2016), 'Does primary care model effect healthcare at the end of life? A population-based retrospective cohort study', Journal of Palliative Medicine, 20(4): 344-351.

Hua, X., G. Erreygers, J. Chalmers, T.-L. Laba and P. Clarke (2017), 'Using administrative data to look at changes in the level and distribution of out-of-pocket medical expenditure: an example using Medicare data from Australia', Health Policy, 121(4): 426-433.

Hunter, T. (1980), 'Pressure groups and the Australian political process: the case of the Australian Medical Association', Journal of Commonwealth \& Comparative Politics, 18(2): 190-206.

Hutchison, B. and R. Glazier (2013), 'Ontario's primary care reforms have transformed the local care landscape, but a plan is needed for ongoing improvement', Health Affairs, 32(4): 695-703.

Independent Hospital Pricing Authority (2015), The Pricing Framework for Australian Public Hospital Services 2016-17, Sydney: IHPA.

Independent Hospital Pricing Authority (2016), Consultation Paper on the Pricing Framework for Australian Public Hospital Services 2017-18, Sydney: IHPA.

Jeon, Y.-H. and H. Kendig (2017), 'Care and Support for Older People', in K. O’Loughlin, C. Browning and H. Kendig (eds), Ageing in Australia: Challenges and Opportunities, New York: Springer, 239-259. 
Johar, M., C. Mu, K. Van Gool and C. Y. Wong (2017), 'Bleeding hearts, profiteers, or both: specialist physician fees in an unregulated market', Health Economics, 26(4): 528-535.

Karmel, R., D. Gibson, P. Anderson, Y. Wells and S. Duckett (2012), 'Care trajectories through community and residential aged care services: disease effects', Ageing and Society, 32(8): $1428-1445$.

Kay, A. (2017), 'Policy failures, policy learning and institutional change: the case of Australian health insurance policy change', Policy \& Politics, 45(1): 87-101.

Kettlewell, N., O. Stavrunova and O. Yerokhin (2018), 'Premium subsidies and demand for private health insurance: results from a regression discontinuity design', Applied Economics Letters, 25(2): 96-101. https://doi.org/10.1080/13504851.2017.1299094.

Kewley, T. H. (1973), Social Security in Australia 1900-72, 2nd edn, Sydney: Sydney University Press.

Kiran, T., A. Kopp and R. H. Glazier (2016), 'Those left behind from voluntary medical home reforms in Ontario, Canada', The Annals of Family Medicine, 14(6): 517-525.

Laberge, M., W. P. Wodchis, J. Barnsley and A. Laporte (2017), 'Hospitalizations for ambulatory care sensitive conditions across primary care models in Ontario, Canada', Social Science \& Medicine, 181: 24-33.

Lavergne, M. R., M. R. Law, S. Peterson, S. Garrison, J. Hurley, L. Cheng and K. McGrail (2016), 'A population-based analysis of incentive payments to primary care physicians for the care of patients with complex disease', Canadian Medical Association Journal, 188(15): E375-E383.

Lavoie, J., A. Boulton and J. Dwyer (2010), 'Analysing contractual environments: lessons from Indigenous health in Canada, Australia and New Zealand', Public Administration, 88(3): 665-679.

Lavoie, J. G. (2004), 'Governed by contracts: the development of indigenous primary health services in Canada, Australia and New Zealand', International Journal of Indigenous Health, 1(1): 6-24.

Mackenzie, L. and L. Clemson (2014), 'Can chronic disease management plans including occupational therapy and physiotherapy services contribute to reducing falls risk in older people?', Australian Family Physician, 43(4): 211-215.

Manzano-Santaella, A. (2010a), 'Disentangling the impact of multiple innovations to reduce delayed hospital discharges', Journal of Health Services Research \& Policy, 15(1): 41-46.

Manzano-Santaella, A. (2010b), 'From bed-blocking to delayed discharges: precursors and interpretations of a contested concept', Health Services Management Research, 23(3): 121-127.

Marchildon, G. P. and B. Hutchison (2016), 'Primary care in Ontario, Canada: new proposals after 15 years of reform', Health Policy, 120(7): 732-738.

Mathews, R. L. and W. R. C. Jay (1972), Federal Finance: Australian Fiscal Federalism from Federation to McMahon, 2nd edn, Melbourne: Thomas Nelson.

McDonald, F. and S. Duckett (2017), 'Regulation, private health insurance and the Australian health system'. McGill Law Journal, 11(1): S31-S60.

McMillan, J. (1992), Commonwealth Constitutional Power Over Health, Canberra: Consumers' Health Forum of Australia.

Menz, H. B. (2009), 'Utilisation of podiatry services in Australia under the Medicare enhanced primary care program, 2004-2008', Journal of Foot and Ankle Research, 2(1): 30.

Morgan, S., M. McMahon, C. Mitton, E. Roughead, R. Kirk, P. Kanavos and D. Menon (2006), 'Centralized drug review processes in Australia, Canada, New Zealand, and the United Kingdom’, Drug Review, 25(2): 337-347. 
Morgan, S. G. and K. Boothe (2016), 'Universal prescription drug coverage in Canada: long-promised yet undelivered', Healthcare Management Forum, 29(6): 247-254.

Morgan, S. G., M.-A. Gagnon, B. Mintzes and J. Lexchin (2016), 'A better prescription: advice for a national strategy on pharmaceutical policy in Canada', Healthcare Policy, 12(1): 18-36.

Mullins, C. D., E. M. Ndiritu, D. M. Yoder, F. T. Shaya and T. A. Taylor (2003), 'Impact of the fourth hurdle on the international pharmaceutical industry', Expert Review of Pharmacoeconomics \& Outcomes Research, 3(2): 169-177.

O'Brady, S., M.-A. Gagnon and A. Cassels (2015), 'Reforming private drug coverage in Canada: inefficient drug benefit design and the barriers to change in unionized settings', Health Policy, 119(2): 224-231.

Ong, R. (2016), 'Financing Aged Care: The Role of Housing Wealth and Intergenerational Relationships', in H. Kendig, P. F. McDonald and J. Piggott (eds), Population Ageing and Australia's Future, Acton, ACT: ANU Press, 281-301.

Osborn, R., D. Squires, M. M. Doty, D. O. Sarnak and E. C. Schneider (2016), 'In new survey of eleven countries, US adults still struggle with access to and affordability of health care', Health Affairs, 35(12): 2327-2336.

Palangkaraya, A. and J. Yong (2005), 'Effects of recent carrot-and-stick policy initiatives on private health insurance coverage in Australia', Economic Record, 81(254): 262-272.

PBS Information Management Section, Pharmaceutical Policy Branch (2016), 'Expenditure and prescriptions twelve months to 30 June 2016', Canberra: Department of Health.

Philippon, D. J. and J. Braithwaite (2008), 'Health system organization and governance in Canada and Australia: a comparison of historical developments, recent policy changes and future implications', Healthcare Policy, 4(1): e168-e186.

Price, K., J. Beilby, H. McElroy, D. Wilkinson, J. Best, S. Morey and K. Mott (2002), 'Uptake of health assessments, care plans and case conferences by general practitioners through the enhanced primary care program between November 1999 and October 2001', Australian Health Review, 25(4): 1.

Productivity Commission (2011), Caring for Older Australians, Canberra: Productivity Commission.

Rhee, J. J., N. A. Zwar and L. A. Kemp (2012), 'Uptake and implementation of advance care planning in Australia: findings of key informant interviews', Australian Health Review, 36(1): 98-104.

Robson, J., S. Hull, R. Mathur and K. Boomla (2014), 'Improving cardiovascular disease using managed care networks in general practice', British Journal of General Practice, 64(622): e268-e274.

Rosen, B. (2018), 'Expanding Canadian Medicare to include a national pharmaceutical benefit: Possible lessons from Israel'. Health Economics, Policy and Law, 13(3-4): 323-343.

Royal Australian College of General Practitioners (2015), Vision for General Practice and a Sustainable Healthcare System, Melbourne: RACGP.

Rudoler, D., R. Deber, J. Barnsley, R. H. Glazier, A. R. Dass and A. Laporte (2015), 'Paying for primary care: the factors associated with physician self-selection into payment models', Health Economics, 24(9): 1229-1242.

Schoen, C., K. Davis, C. DesRoches, K. Donelan and R. Blendon (2000), 'Health insurance markets and income inequality: findings from an international health policy survey', Health Policy, 51: 67-85.

Schoen, C., R. Osborn, D. Squires, M. Doty R. Pierson and S. Applebaum (2011), 'New 2011 survey of patients with complex care needs in eleven countries finds that care is often poorly coordinated', Health Affairs, 30(12): 2437-2448. 
Schwarzer, R., U. Rochau, K. Saverno, B. Jahn, B. Bornschein, N. Muehlberger, M. FlatscherThoeni, P. Schnell-Inderst, G. Sroczynski, M. Lackner, I. Schall, A. Hebborn, K. Pugner, A. Fehervary, D. Brixner and U. Siebert (2015), 'Systematic overview of cost-effectiveness thresholds in ten countries across four continents', Journal of Comparative Effectiveness Research, 4(5): 485-504.

Scott, A., S. Schurer, P. H. Jensen and P. Sivey (2009), 'The effects of an incentive program on quality of care in diabetes management', Health Economics, 18(9): 1091-1108.

Scott, A., P. Sivey, D. A. Ouakrim, L. Willenberg, L. Naccarella, J. Furler and D. Young (2011), 'The effect of financial incentives on the quality of health care provided by primary care physicians'. The Cochrane Database of Systematic Reviews (9): 1-59.

Scotton, R. B. and C. R. Macdonald (1993), The Making of Medibank Volume 76 Sydney: School of Health Services Management, University of NSW.

Senate. Standing Committee on Social Affairs Science Technology (Chair: Senator Michael Kirby) (2002), 'The health of Canadians: the federal role', Final report on the State of the Health Care System in Canada, Senate of Canada, Ottawa.

Sloan, C. (1995), A History of the Pharmaceutical Benefits Scheme 1947-1992, Canberra: Commonweath Department of Human Services and Health.

Smith, A. J. and P. McGettigan (2000), 'Quality use of medicines in the community: the Australian experience', British Journal of Clinical Pharmacology, 50(6): 515-519.

Steering Committee for the Review of Commonwealth/State Service Provision (SCRCSSP) (2017), Report on Government Services 2017, Canberra: Productivity Commission.

Struckmann, V., W. Quentin, R. Busse and E. van Ginneken (2016), How to strengthen financing mechanisms to promote care for people with multimorbidity in Europe? Policy Brief, European Observatory on Health Systems and Policies, Utecht.

Suchowersky, A., O. Suchowersky and S. Duckett (2012), 'Can Alberta's primary care networks provide any lessons for Medicare Locals?', Medical Journal of Australia, 196(1): 27-28.

Sunderland, N., P. Harris, K. Johnstone, L. Del Fabbro and E. Kendall (2015), 'Exploring health promotion practitioners' experiences of moral distress in Canada and Australia', Global Health Promotion, 22(1): 32-45.

Swerissen, H. and S. Duckett (2007), 'Federalism and Health: Negotiating the Problems of "Fiscal Squabbles", "Waiting" and "Waste"', in S. Barraclough and H. Gardner (eds), Analysing Australian Health Policy: A Problem Orientated Approach, Marrickville: Elsevier, 69-82.

Swerissen, H. and S. Duckett (2016), Chronic Failure in Primary Care, Melbourne, VIC: Grattan Institute.

Swerissen, H. and S. Duckett (2017), Building Better Foundations for Primary Care, Melbourne, VIC: Grattan Institute.

Tanenbaum, S. J. (2009), 'Pay for performance in Medicare: evidentiary irony and the politics of value', Journal of Health Politics Policy and Law, 34(5): 717-746.

Tempier, R., G. N. Meadows, H.-M. Vasiliadis, K. E. Mosier, A. Lesage, A. Stiller, A. Graham and M. Lepnurm (2009), 'Mental disorders and mental health care in Canada and Australia: comparative epidemiological findings', Social Psychiatry and Psychiatric Epidemiology, 44(1): 63.

Tenbensel, T., J. Dwyer and J. Lavoie (2014), 'How not to kill the golden goose: reconceptualizing accountability environments of third-sector organizations', Public Management Review, 16(7): 925-944.

Tsiachristas, A., C. Dikkers, M. R. S. Boland and M. P. M. H. Rutten-van Mölken (2013), 'Exploring payment schemes used to promote integrated chronic care in Europe', Health Policy, 113(3): 296-304. 
Varabyova, Y. and J. Schreyögg (2013), 'International comparisons of the technical efficiency of the hospital sector: panel data analysis of OECD countries using parametric and non-parametric approaches', Health Policy, 112(1-2): 70-79.

Weekes, L. M., J. M. Mackson, M. Fitzgerald and S. R. Phillips (2005), 'National prescribing service: creating an implementation arm for national medicines policy', British Journal of Clinical Pharmacology, 59(1): 112-116.

Wheelwright, K. (1995), 'Commonwealth and state powers in health: a constitutional diagnosis', Monash University Law Review, 21(1): 52-83.

Wilkinson, D., H. McElroy, J. Beilby, K. Mott, K. Price, S. Morey and J. Best (2002a), 'Uptake of health assessments, care plans and case conferences by general practitioners through the Enhanced Primary Care program between November 1999 and October 2001', Australian Health Review, 25(4): 1-11.

Wilkinson, D., H. McElroy, J. Beilby, K. Mott, K. Price, S. Morey and J. Best (2002b), 'Characteristics of general practitioners that provided health assessments, care plans or case conferences, as part of the Enhanced Primary Care program', Australian Health Review, 25(6): 121.

Wilkinson, D., H. McElroy, J. Beilby, K. Mott, K. Price, S. Morey and J. Best (2003), 'Are socio-economically disadvantaged Australians making more or less use of the enhanced primary care Medicare benefit schedule item numbers?', Australian Health Review, 26(3): 43-49.

Wiltshire, K. (1992), 'Australia's new federalism: recipes for marble cakes', Publius, 22(3): $165-180$.

Wranik, D. W. and M. Durier-Copp (2009), 'Physician remuneration methods for family physicians in Canada: expected outcomes and lessons learned', Health Care Analysis, 18(1): 35-59.

Zwar, N., O. Hermiz, E. Comino, T. Shortus, J. Burns and M. Harris (2007), 'Do multidisciplinary care plans result in better care for patients with type 2 diabetes?', Australian Family Physician, 36(1/2): 85.

Zwar, N. A., E. J. Comino, I. Hasan and M. F. Harris (2005), 'General practitioner views on barriers and facilitators to implementation of the Asthma $3+$ Visit Plan', The Medical Journal of Australia, 183(2): 64-67. 